\title{
Characteristics of Electronic Cigarette Use Among Middle and High School Students - United States, 2015
}

\author{
Tushar Singh, MD, PhD ${ }^{1,2}$; Sara Kennedy, MPH${ }^{1}$; Kristy Marynak, MPP ${ }^{1}$; Alexander Persoskie, PhD 3 ; Paul Melstrom, PhD ${ }^{1}$; Brian A. King, PhD ${ }^{1}$
}

Electronic cigarettes (e-cigarettes) are now the most commonly used tobacco product among U.S. youths $(1,2)$; in 2015 , $5.3 \%$ of middle school students and $16.0 \%$ of high school students reported using e-cigarettes in the past 30 days (1). However, limited information exists on the e-cigarette product types and brands used and the substances used in these products by youths. CDC and the Food and Drug Administration (FDA) analyzed data from the 2015 National Youth Tobacco Survey (NYTS) to examine the characteristics of e-cigarette use among U.S. middle (grades 6-8) and high (grades 9-12) school students in 2015, including types of products used, brands of products used, and whether substances other than nicotine were used with the products. Among respondents reporting ever having used an e-cigarette, $14.5 \%$ used only disposable e-cigarettes, $53.4 \%$ used only rechargeable/refillable e-cigarettes, and $32.1 \%$ used both types. Two of the most commonly used e-cigarette brands were blu (26.4\%, 1.65 million youths) and VUSE (12.2\%, 760,000 youths); half of students $(50.7 \%, 3.18$ million) did not know the brand of e-cigarette they used. One third (32.5\%) of those who reported ever using an e-cigarette also reported having used e-cigarettes for substances other than nicotine. Preventing youths from beginning use of any tobacco product, including e-cigarettes, is critical to tobacco use prevention and control strategies in the United States (3). Monitoring the characteristics of e-cigarette use among youths, including product types, brands, and ingredients, is important to inform strategies to prevent and reduce e-cigarette use among youths.

The NYTS is a cross-sectional, school-based, self-administered, pencil-and-paper questionnaire administered to U.S. middle and high school students.* A three-stage cluster sampling procedure was used to generate a nationally representative sample of U.S. students attending public and private schools in grades 6-12. In 2015, 17,711 students completed the NYTS; the response rate was $63.4 \%$.

The analytic sample included 4,021 students who reported ever using e-cigarettes, even once or twice. ${ }^{\dagger}$ Respondents were asked what types of e-cigarettes they had used (disposable, rechargeable/refillable, or both), what brands of e-cigarettes they had ever tried (blu, NJOY, MarkTen, Logic, VUSE,

\footnotetext{
*https://www.cdc.gov/tobacco/data_statistics/surveys/nyts/index.htm.

$\dagger$ Respondents with missing responses for any measure included in the analysis $(n=652)$ were excluded from the sample.
}

Finiti, Starbuzz, Fantasia, some other brand not listed, or don't know), and if they had ever used an e-cigarette for any substance other than nicotine (yes or no). ${ }^{\S}$ Data were weighted to account for the complex survey design and to adjust for nonresponse. Among e-cigarette users, prevalence estimates and $95 \%$ confidence intervals are reported for type of e-cigarette ever used, brands, and whether e-cigarettes were used for any substance other than nicotine. Estimates were calculated overall and by school level (middle or high), sex, and race/ethnicity (non-Hispanic white, non-Hispanic black, Hispanic, or nonHispanic other). Population estimates rounded down to the nearest 10,000 were also computed. Estimates with a relative standard error greater than 30\% were not reported.

In $2015,13.5 \%$ of middle and $37.7 \%$ of high school students had ever used an e-cigarette. Among all students reporting having ever used an e-cigarette, $14.5 \%$ had used only disposable e-cigarettes, $53.4 \%$ had used only rechargeable/refillable e-cigarettes, and $32.1 \%$ had used both types (Table). Use of both types of e-cigarettes was higher among males compared with females, and non-Hispanic white and Hispanic students compared with non-Hispanic black students.

Among students who had ever used an e-cigarette, approximately half $(50.7 \%, 3.18$ million) did not know the brand of e-cigarette they had used. The most commonly reported e-cigarette brand was blu (26.4\%, 1.65 million), followed by "other" brands $(24.2 \%, 1.52$ million); VUSE (12.2\%, 760,000); Starbuzz (5.0\%, 310,000); Logic (4.6\%, 280,000); NJOY (4.5\%, 270,000); Fantasia (4.1\%, 250,000); MarkTen $(2.2 \%, 140,000)$; and Finiti $(1.4 \%, 90,000)$ (Figure).

Approximately one third of students who had ever used an e-cigarette (32.5\%) reported having used (at least once) an e-cigarette for a substance other than nicotine (Table). Use of e-cigarettes for a substance other than nicotine was higher among males compared with females, and non-Hispanic white and Hispanic students compared with non-Hispanic black students. The proportion of e-cigarette users who used an e-cigarette for a substance other than nicotine was similar among middle (33.7\%) and high (32.2\%) school students.

\footnotetext{
\$The wording on the survey instrument was as follows: "Thinking about all types of electronic cigarettes or e-cigarettes, have you used the disposable kind or rechargeable/refillable tank kind?"; "What brands of electronic cigarettes or e-cigarettes have you ever tried? (CHOOSE ALL THAT APPLY)"; "Have you ever used an electronic cigarette device for any other substance other than for nicotine?"
} 
Please note: An erratum has been published for this issue. To view the erratum, please click here.

Morbidity and Mortality Weekly Report

TABLE. Percentages of middle and high school students who reported ever using an e-cigarette, including using an e-cigarette for a substance other than nicotine, by type and brand of e-cigarette, sex, and race/ethnicity - United States, 2015*

\begin{tabular}{|c|c|c|c|c|c|c|c|}
\hline \multirow[b]{3}{*}{ Characteristic } & \multirow[b]{2}{*}{ Total } & \multicolumn{2}{|c|}{ Sex } & \multicolumn{4}{|c|}{ Race/Ethnicity } \\
\hline & & Male & Female & $\begin{array}{l}\text { Non-Hispanic } \\
\text { white }\end{array}$ & $\begin{array}{c}\text { Non-Hispanic } \\
\text { black }\end{array}$ & Hispanic & $\begin{array}{l}\text { Non-Hispanic } \\
\text { other }\end{array}$ \\
\hline & $\%(95 \% \mathrm{Cl})$ & $\%(95 \% \mathrm{Cl})$ & $\%(95 \% \mathrm{Cl})$ & $\%(95 \% \mathrm{Cl})$ & $\%(95 \% \mathrm{Cl})$ & $\%(95 \% \mathrm{Cl})$ & $\%(95 \% \mathrm{Cl})$ \\
\hline \multicolumn{8}{|l|}{ Type } \\
\hline Only disposable & $14.5(12.3-17.0)$ & $13.7(11.3-16.6)$ & $15.4(12.6-8.7)$ & $11.3(9.2-13.7)$ & $24.1(18.0-31.5)$ & $18.3(15.1-22.0)$ & $12.6(8.5-18.2)$ \\
\hline Only rechargeable/refillable & $53.4(50.2-56.6)$ & $52.2(48.7-55.8)$ & $54.8(50.9-58.6)$ & $54.2(50.8-57.6)$ & $57.6(50.7-64.2)$ & $49.1(43.7-54.4)$ & $59.6(52.2-66.5)$ \\
\hline Both & $32.1(29.9-34.3)$ & $34.0(31.0-37.2)$ & $29.8(27.2-32.6)$ & $34.5(31.6-37.6)$ & $18.3(14.6-22.8)$ & $32.6(28.7-36.8)$ & $27.9(22.2-34.3)$ \\
\hline \multicolumn{8}{|c|}{ ( } \\
\hline blu & $26.4(23.9-29.1)$ & $28.1(24.9-31.6)$ & $24.4(21.5-27.5)$ & $25.7(22.5-29.1)$ & $35.4(29.7-41.6)$ & $25.3(21.4-29.6)$ & $22.5(15.6-31.2)$ \\
\hline VUSE & $12.2(10.6-13.9)$ & $13.5(11.2-16.1)$ & $10.7(9.0-12.6)$ & $12.2(10.3-14.3)$ & $11.9(8.0-17.4)$ & $12.5(10.0-15.6)$ & $11.2(8.2-15.2)$ \\
\hline $\begin{array}{l}\text { NJOY, MarkTen, Logic, Finiti, } \\
\text { Starbuzz, and/or Fantasia }\end{array}$ & $14.9(13.5-16.4)$ & $16.2(14.1-18.4)$ & $13.4(11.8-15.2)$ & $14.4(12.5-16.5)$ & $11.4(8.4-15.3)$ & $17.4(14.6-20.6)$ & $14.4(11.0-18.6)$ \\
\hline $\begin{array}{l}\text { Other brand not listed on } \\
\text { questionnaire }\end{array}$ & $24.2(22.3-26.3)$ & $29.5(26.6-32.5)$ & $18.1(16.2-20.1)$ & $25.8(23.5-28.3)$ & $17.2(12.3-23.5)$ & $21.3(18.3-24.6)$ & $36.5(27.7-46.3)$ \\
\hline Did not know the brand name & $50.7(48.3-53.0)$ & $44.4(41.6-47.3)$ & $58.1(55.2-60.9)$ & $50.9(47.9-53.8)$ & $45.4(38.5-52.5)$ & $53.4(49.0-57.7)$ & $43.9(37.5-50.5)$ \\
\hline \multicolumn{8}{|c|}{ Ever used e-cigarette for substance other than nicotine } \\
\hline Yes & $32.5(30.2-34.9)$ & $36.9(34.0-40.0)$ & $27.2(24.6-29.9)$ & $32.6(30.0-35.4)$ & $26.0(19.5-33.9)$ & $33.7(30.3-37.4)$ & $36.9(29.1-45.4)$ \\
\hline No & $67.5(65.1-69.8)$ & $63.1(60.0-66.0)$ & $72.8(70.1-75.4)$ & $67.4(64.6-70.0)$ & $74.0(66.1-80.5)$ & $66.3(62.6-69.7)$ & $63.1(54.6-70.9)$ \\
\hline \multicolumn{8}{|l|}{ Middle school } \\
\hline \multicolumn{8}{|l|}{ Type } \\
\hline Only disposable kind & $17.8(13.5-22.9)$ & $17.2(12.0-24.0)$ & $18.5(14.3-23.6)$ & $13.6(10.0-18.2)$ & $28.7(20.6-38.4)$ & $20.7(14.1-29.4)$ & -n \\
\hline Only rechargeable/refillable kind & $61.0(55.5-66.2)$ & $61.4(54.0-68.2)$ & $60.5(54.1-66.6)$ & $62.8(56.6-68.6)$ & $57.3(46.6-67.4)$ & $59.4(48.8-69.2)$ & $60.8(46.3-73.5)$ \\
\hline Both & $21.3(17.8-25.2)$ & $21.5(16.7-27.1)$ & $21.0(16.6-26.2)$ & $23.6(18.9-29.1)$ & $14.0(8.3-22.7)$ & $19.9(14.4-26.8)$ & $22.6(13.2-35.9)$ \\
\hline \multicolumn{8}{|l|}{ Brand $^{\dagger}$} \\
\hline blu & $29.4(25.0-34.3)$ & $32.4(27.5-37.8)$ & $25.7(20.1-32.2)$ & $26.5(20.7-33.2)$ & $44.8(34.6-55.4)$ & $28.9(21.8-37.3)$ & $28.7(17.7-43.1)$ \\
\hline VUSE & $14.0(11.7-16.8)$ & $15.6(12.1-19.9)$ & $12.0(9.1-15.7)$ & $12.9(9.7-16.9)$ & $15.6(8.4-27.1)$ & $15.2(11.1-20.4)$ & $15.1(8.2-26.1)$ \\
\hline $\begin{array}{l}\text { NJOY, MarkTen, Logic, Finiti, } \\
\text { Starbuzz, and/or Fantasia }\end{array}$ & $14.6(12.1-17.5)$ & $14.4(11.6-17.7)$ & $14.8(11.0-19.7)$ & $12.8(10.4-15.7)$ & - & $19.2(14.3-25.4)$ & - \\
\hline $\begin{array}{l}\text { Other brand not listed on } \\
\text { questionnaire }\end{array}$ & $19.6(16.7-22.8)$ & $21.3(17.3-25.8)$ & $17.4(13.7-21.8)$ & $20.4(15.9-25.8)$ & - & $18.6(13.6-24.9)$ & $25.3(14.4-40.4)$ \\
\hline Didn't know brand & $47.6(44.3-50.9)$ & $43.6(38.8-48.6)$ & $52.7(47.7-57.6)$ & $50.3(45.8-54.9)$ & $36.8(25.6-49.7)$ & $46.9(41.1-52.9)$ & $48.2(32.1-64.6)$ \\
\hline \multicolumn{8}{|c|}{ Ever used e-cigarette for substance other than nicotine } \\
\hline Yes & $33.7(29.2-38.4)$ & $35.6(30.7-40.9)$ & $31.2(25.5-37.4)$ & $31.8(25.6-38.8)$ & $22.3(14.4-32.8)$ & $39.4(33.4-45.7)$ & $42.5(25.8-61.1)$ \\
\hline No & $66.3(61.6-70.8)$ & $64.4(59.1-69.3)$ & $68.8(62.6-74.5)$ & $68.2(61.2-74.4)$ & $77.7(67.2-85.6)$ & $60.6(54.3-66.6)$ & $57.5(38.9-74.2)$ \\
\hline \multicolumn{8}{|l|}{ High School } \\
\hline \multicolumn{8}{|l|}{ Type } \\
\hline Only disposable kind & $13.6(11.3-16.4)$ & $12.8(10.2-15.9)$ & $14.6(11.3-18.7)$ & $10.7(8.3-13.7)$ & $22.7(16.1-30.9)$ & $17.5(14.1-21.5)$ & $11.6(7.6-17.2)$ \\
\hline Only rechargeable/refillable kind & $51.4(48.0-54.8)$ & $49.7(46.2-53.3)$ & $53.4(48.9-57.8)$ & $52.2(48.5-56.0)$ & $57.6(49.9-65.0)$ & $45.6(40.3-51.1)$ & $59.3(51.4-66.7)$ \\
\hline Both & $34.9(32.5-37.5)$ & $37.5(34.1-0.9)$ & $32.0(28.8-35.4)$ & $37.1(33.7-40.5)$ & $19.7(14.8-25.6)$ & $36.9(32.8-41.1)$ & $29.1(22.9-36.3)$ \\
\hline \multicolumn{8}{|c|}{ 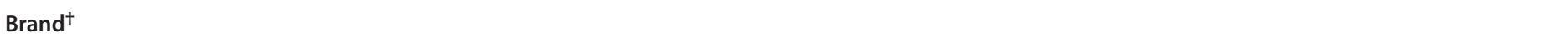 } \\
\hline blu & $25.6(22.6-28.8)$ & $27.0(23.1-31.2)$ & $24.0(20.6-27.9)$ & $25.5(21.5-30.0)$ & $32.6(26.9-38.8)$ & $24.1(19.9-28.8)$ & $21.0(13.2-31.8)$ \\
\hline VUSE & $11.7(10.0-13.7)$ & $12.9(10.3-16.0)$ & $10.4(8.5-12.6)$ & $12.0(9.8-14.6)$ & $10.8(6.8-16.8)$ & $11.6(8.8-15.2)$ & $10.3(6.9-15.1)$ \\
\hline $\begin{array}{l}\text { NJOY, MarkTen, Logic, Finiti, } \\
\text { Starbuzz, and/or Fantasias }\end{array}$ & $15.0(13.3-16.8)$ & $16.6(14.3-19.2)$ & $13.0(11.3-15.0)$ & $14.7(12.5-17.2)$ & $12.0(8.6-16.5)$ & $16.8(13.4-20.9)$ & $14.4(10.2-19.9)$ \\
\hline $\begin{array}{l}\text { Other brand not listed on } \\
\text { questionnaire }\end{array}$ & $25.5(23.3-27.8)$ & $31.7(28.4-35.1)$ & $18.2(16.2-20.4)$ & $27.1(24.5-29.7)$ & $17.4(12.2-24.4)$ & $22.2(18.5-26.4)$ & $39.2(29.3-50.0)$ \\
\hline Didn't know brand & $51.5(48.8-54.2)$ & $44.6(41.4-47.9)$ & $59.5(56.1-62.8)$ & $51.0(47.3-54.7)$ & $48.0(40.7-55.4)$ & $55.5(50.4-60.6)$ & $42.9(35.4-50.8)$ \\
\hline \multicolumn{8}{|c|}{ Ever used e-cigarette for substance other than nicotine } \\
\hline Yes & $32.2(29.9-34.5)$ & $37.3(34.3-40.4)$ & $26.2(23.4-29.1)$ & $32.8(30.3-35.5)$ & $27.2(20.5-35.2)$ & $31.9(28.4-35.5)$ & $35.5(26.5-45.7)$ \\
\hline No & $67.8(65.5-70.1)$ & $62.7(59.6-65.7)$ & $73.8(70.9-76.6)$ & $67.2(64.5-69.7)$ & $72.8(64.8-79.5)$ & $68.1(64.5-71.6)$ & $64.5(54.3-73.5)$ \\
\hline
\end{tabular}

* Respondents with missing data for any demographic or analysis variable and respondents who reported never e-cigarette use on the brand or type question were excluded from the analysis.

${ }^{\dagger}$ Categories are not mutually exclusive.

$\S$ Because of small sample sizes, estimates for these six e-cigarette brands were combined into one category.

१ Relative standard error $>30$. 


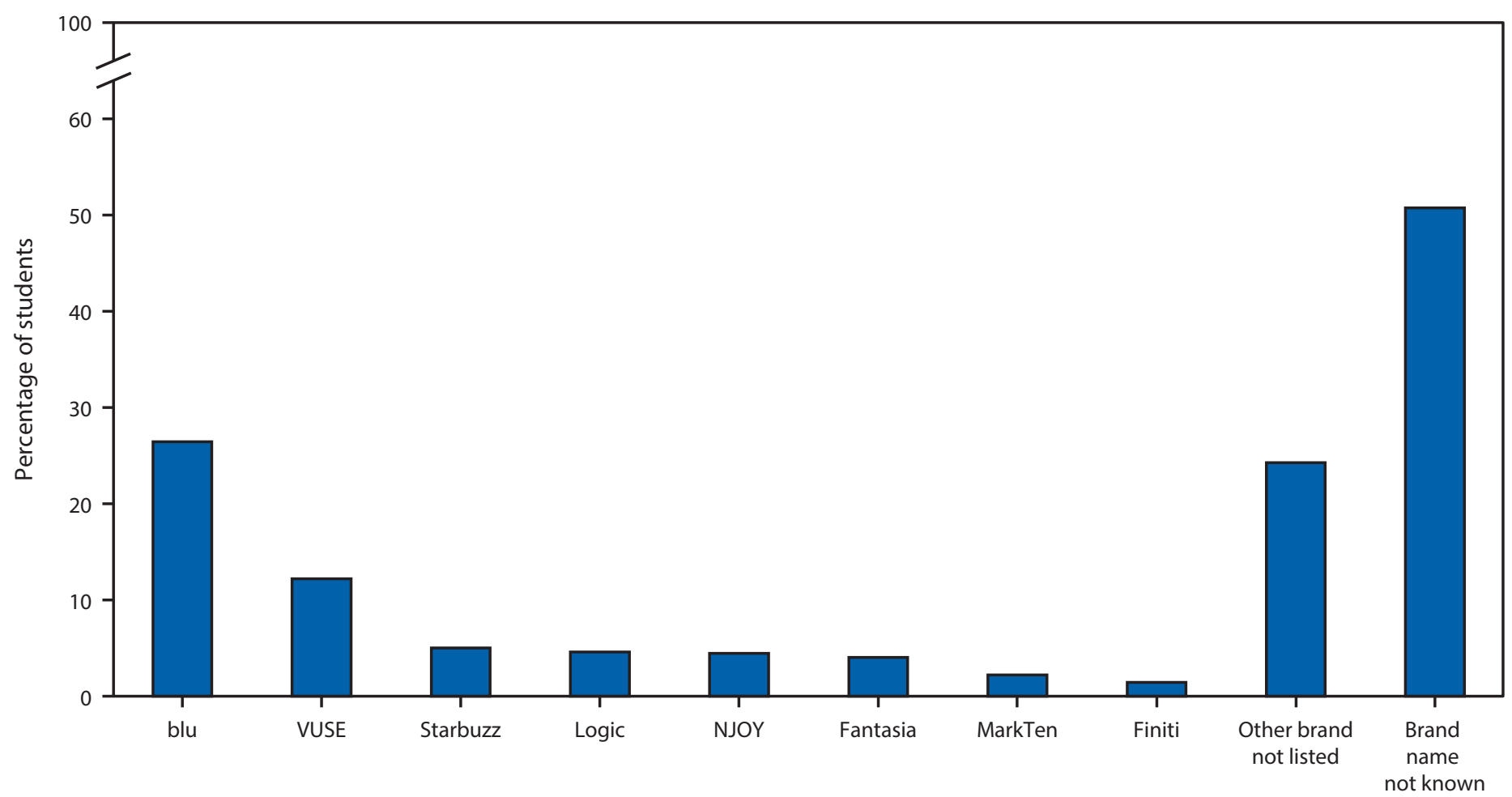

Brand name

* Categories are not mutually exclusive.

\section{Discussion}

Among middle and high school students who have ever used e-cigarettes, most report using rechargeable/refillable e-cigarettes, and approximately one third report having used e-cigarettes for substances other than nicotine. Among students who have ever used an e-cigarette, the most commonly reported brand was blu; approximately half of students did not know the brand of e-cigarettes they have used. Tobacco use and addiction typically begin during adolescence $(3,4)$, and the U.S. Surgeon General has concluded that the use of products containing nicotine in any form among youth, including in e-cigarettes, is unsafe (5). Comprehensive and sustained strategies are critical to prevent and reduce the use of e-cigarettes among U.S. youths (5).

Most e-cigarette users (53.4\%) reported using a rechargeable/ refillable e-cigarette, $32.1 \%$ used both rechargeable/refillable and disposable devices, and $14.5 \%$ used a disposable device only. Disposable e-cigarettes are often similar in size and shape to conventional cigarettes; rechargeable/refillable e-cigarettes, which come in various shapes and sizes, can be readily customized by the user to include various levels of nicotine, flavors, and other ingredients. In addition, refillable e-cigarettes come in multiple device types with a range of possible voltages and other characteristics that can affect the heating of the e-liquid, release of nicotine, and formation of toxicants (5). Variations in the efficiency of nicotine delivery might affect the products' addiction risk (G). Because e-cigarettes are the most commonly used tobacco product among middle and high school students, and nicotine exposure from any source is harmful for youths (5), it is critical that comprehensive tobacco control and prevention strategies address the diversity of e-cigarette products used by U.S. youths.

Most students did not know the brand of e-cigarettes they used. Among those who did know the brand of e-cigarettes they used, blu and VUSE were the most commonly reported brands. The higher reported use of blu and VUSE products might be explained, in part, by the fact that they are owned by large cigarette manufacturers, and thus, are among the most heavily advertised e-cigarette brands in the United States (7). Approximately $70 \%$ of U.S. middle and high school students are exposed to e-cigarette advertising (8), and youths' exposure to e-cigarette advertising is associated with current use (5). Moreover, certain e-cigarette marketers are using advertising tactics similar to those used in the past to market conventional cigarettes, employing themes and imagery conveying independence, rebellion, and sexual attractiveness (5). The unrestricted 
marketing of e-cigarettes could contribute to increasing use of these products among youths (5) and has the potential to undermine progress in preventing tobacco product use and promoting a tobacco-free lifestyle among youths $(3,5)$.

Approximately one third of students reported using e-cigarettes for substances other than nicotine. This aligns with previous research, including one study of Connecticut high school students, in which $18.0 \%$ of those who had ever used an e-cigarette reported using cannabis in an e-cigarette (9). The present study's finding suggests that the remaining majority of users have used e-cigarettes to consume nicotine. In contrast, a recent study using a different self-reported measure found that between $13 \%$ and $22 \%$ of students in grades 8,10 , and 12 who had ever used an e-cigarette reported using nicotine the last time they had used an e-cigarette (10). In the present analysis, it is unknown whether students who had used an e-cigarette for a non-nicotine substance had also used an e-cigarette for nicotine, which might underestimate nicotine use. Additional research is warranted on the presence of nicotine in e-cigarettes, including from data sources that might not be subject to the same limitations as self-reported data among youth, such as retail sales data (5). Nicotine content in e-cigarettes is of public health concern because exposure to nicotine is the main cause of tobacco product dependence (3), and nicotine exposure during adolescence, a critical period for brain development, can cause addiction, can harm brain development, and could lead to sustained tobacco product use among youths $(3,5)$.

The findings in this report are subject to at least five limitations. First, NYTS samples middle and high school students from public and private schools in the United States; therefore, these findings might not be generalizable to youths who are home-schooled, have dropped out of school, or are in detention centers. Second, data were self-reported; thus, the findings are subject to bias. Third, not all brands of e-cigarettes were assessed; one fourth of students reported having used brands not mentioned in the questionnaire. Fourth, response bias might have affected the results because the NYTS response rate in 2015 was $63.4 \%$. Finally, it was not possible to ascertain the specific substances used by students reporting that they had used a substance other than nicotine in an e-cigarette.

Comprehensive and sustained strategies are warranted to prevent and reduce the use of all tobacco products, including e-cigarettes, among U.S. youths $(3,5)$. Regulation of the manufacturing, distribution, and marketing of tobacco products by FDA, 9 coupled with full implementation of comprehensive tobacco control and prevention strategies at CDC-recommended

\footnotetext{
Thttps://www.federalregister.gov/a/2016-10685.
}

\section{Summary \\ What is already known about this topic?}

In 2015, e-cigarettes were the most commonly used tobacco product among U.S. middle and high school students. Tobacco use and addiction typically begin during adolescence, and the use of products containing nicotine in any form among youth, including in e-cigarettes, is unsafe.

What is added by this report?

Among U.S. middle and high school students who have ever used e-cigarettes, most report using rechargeable/ refillable e-cigarettes, and approximately one third report using e-cigarettes for substances other than nicotine. Among students who reported ever using e-cigarettes, the most commonly reported brand was blu ( $26.4 \%, 1.65$ million youths); approximately half of students did not know the brand of e-cigarettes they have used.

What are the implications for public health practice? Comprehensive and sustained strategies are warranted to prevent and reduce the use of all tobacco products, including e-cigarettes, among U.S. youths. Monitoring the characteristics of e-cigarette use among youths, including product types, brands, and ingredients, is important to guide measures to prevent and reduce the use of e-cigarettes among youths.

funding levels, could reduce youths' e-cigarette use and initiation $(3,5)$. In addition, monitoring the characteristics of e-cigarette use among youths, including product types, brands, and ingredients, is important to guide measures to prevent and reduce use of e-cigarettes among youths.

${ }^{1}$ Office on Smoking and Health, National Center for Chronic Disease Prevention and Health Promotion, CDC; ${ }^{2}$ Epidemic Intelligence Service, CDC; ${ }^{3}$ Center for Tobacco Products, Food and Drug Administration.

Corresponding author: Tushar Singh, tsingh@cdc.gov, 770-488-4252.

\section{References}

1. Singh T, Arrazola RA, Corey CG, et al. Tobacco use among middle and high school students-United States, 2011-2015. MMWR Morb Mortal Wkly Rep 2016;65:361-7. http://dx.doi.org/10.15585/mmwr.mm6514a1

2. National Institute on Drug Abuse. Monitoring the future study: trends in prevalence of various drugs. Rockville, MD: National Institute on Drug Abuse; 2016. https://www.drugabuse.gov/trends-statistics/monitoring-future/ monitoring-future-study-trends-in-prevalence-various-drugs

3. US Department of Health and Human Services. The health consequences of smoking - 50 years of progress: a report of the Surgeon General. Atlanta, GA: US Department of Health and Human Services, CDC; 2014. https://www.surgeongeneral.gov/library/reports/50-years-ofprogress/full-report.pdf

4. US Department of Health and Human Services. Preventing tobacco use among youth and young adults. Atlanta, GA: US Department of Health and Human Services, CDC; 2012. https://www.surgeongeneral. gov/library/reports/preventing-youth-tobacco-use/

5. US Department of Health and Human Services. E-cigarette use among youth and young adults: a report of the Surgeon General. Atlanta, GA: US Department of Health and Human Services, CDC; 2016. https://ecigarettes.surgeongeneral.gov/documents/2016_SGR_Full_Report_ non-508.pdf 
6. Cobb CO, Hendricks PS, Eissenberg T. Electronic cigarettes and nicotine dependence: evolving products, evolving problems. BMC Med 2015;13:119. http://dx.doi.org/10.1186/s12916-015-0355-y

7. Truth Initiative. Vaporized: majority of youth exposed to e-cigarette advertising. Washington, DC: Truth Initiative; 2015. http://truthinitiative. org/research/vaporized-majority-youth-exposed-e-cigarette-advertising

8. Singh T, Marynak K, Arrazola RA, Cox S, Rolle IV, King BA. Vital signs: exposure to electronic cigarette advertising among middle school and high school students-United States, 2014. MMWR Morb Mortal Wkly Rep 2016;64:1403-8. http://dx.doi.org/10.15585/mmwr.mm6452a3
9. Morean ME, Kong G, Camenga DR, Cavallo DA, Krishnan-Sarin S. High school students' use of electronic cigarettes to vaporize cannabis. Pediatrics 2015;136:611-6. http://dx.doi.org/10.1542/peds.2015-1727

10. Miech R, Patrick ME, O'Mailey PM, Johnston LD. What are kids vaping? Results from a national survey of US adolescents. Tobacco Control 2016. Epub August 25, 2016. http://dx.doi.org/10.1136/ tobaccocontrol-2016-053014 